\title{
O personal trainer e o cuidado de si: uma perspectiva de mediação profissional
}

\begin{abstract}
Resumo: O presente artigo propõe discutir o "cuidado de si" como uma possibilidade de mediação profissional entre o professor de Educação Física que atua como treinador personalizado - personal trainer - e seu cliente. Para tal, foi realizada uma revisão bibliográfica sobre o tema "cuidado de si", utilizando como aporte teórico as obras de Michel Foucault, seguida da tentativa de articulação com o pensamento de autores como Deleuze, Baudrillard, Bauman, Melucci e Sant'Anna, entre outros.
\end{abstract}

Palavras-Chave: Cuidado de Si. Personal Trainer. Corpo.

\section{INTRODUÇÃO}

Atualmente, quando os meios de comunicação de grande circulação destacam a atividade física orientada e individualizada, logo emerge o "especialista" em forma física, ou seja, o personal trainer ou treinador personalizado.

Com ares de "modismo", esta perspectiva de atividade foi introduzida no Brasil, segundo Rodrigues (1996), no início dos anos 90 do século XX. Entendo que esta perspectiva parece ter agregado novos papéis às corriqueiras atividades exercidas pelo professor de Educação Física no segmento do Fitness. Desta forma, Rodrigues (1996) parece delinear um desses novos papéis quando define o profissional Personal Training como uma "super microempresa" que vende serviços de aptidão e visa conquistar o cliente, satisfazê-lo e mantê-lo fiel.

\footnotetext{
- Mestranda no PPGCMH da ESEF UFRGS. Porto Alegre-RS, Brasil. E-mail: cibele.bossle@terra.com.br
} 
Neste sentido, o segmento personal trainer parece incorporar e reproduzir o discurso empresarial e é na bibliografia encontrada sobre o tema que esta linguagem se torna visível. Os livros de Brooks (2000; 2004); Deliberador (1998); Domingues Filho (2001); Monteiro (1998); Monteiro (2000); Novaes (1998); Novaes; Vianna (2003); O'Brien (1998); Oliveira (1999); Rodrigues (1996); Rodrigues; Contursi (1998), em sua maioria, apresentam-se como manuais para professores de Educação Física que desejam trabalhar na área de treinamento personalizado. Palavras como cliente, concorrência, negociação, marketing, credibilidade, serviço, propaganda, consumidor, produto, mercado, parcerias são apresentadas de maneira recorrente nesses livros/manuais. Eles trazem, também, orientações de como se tornar um profissional de sucesso, estratégias de marketing pessoal, aspectos contratuais, montagem de programas de treinamento e a preocupação com a crescente concorrência no mercado da atividade física.

Sibillia (2002, p. 36) defende que "[...] enquanto os cidadãos do mundo globalizado vão incorporando o papel de consumidores, a lógica da empresa passa a permear a totalidade do corpo social, impondo o seu modelo a todas as instituições". Poderíamos pensar, então, o cliente como o consumidor do serviço de aptidão vendido pelo personal trainer.

Neste sentido, Bauman (1999, p. 91) sublinha que os consumidores são "[...] primeiro e acima de tudo acumuladores de sensações; são colecionadores de coisas apenas no sentido secundário e derivado". Portanto, pensando o personal trainer como uma empresa e o seu cliente como consumidor de sua prestação de serviço, que sensações almejaria este cliente na relação com o seu treinador personalizado?

Propondo a discussão desta questão, busquei na bibliografia do "cuidado de si" uma possibilidade de início de investigação.

Movimento, Porto Alegre, v. 14, n. 01, p. 187-198, janeiro/abril de 2008. 


\section{Cuidado de Si e o Personal Trainer}

A partir das idéias apresentadas por Foucault (2006) em "A hermenêutica do sujeito" podemos pensar que os filósofos da Grécia antiga foram os primeiros pensadores de epiméleia heautoû, que pode ser entendido como o cuidado de si mesmo, a preocupação consigo, o fato de ocupar-se consigo mesmo. Assim, Sócrates apresenta-se como "o mestre do cuidado de si", tendo como função principal e fundamental estimular os outros indivíduos a terem cuidados consigo mesmos, ofício que lhe foi confiado pelos deuses. Os textos dos primeiros séculos, de acordo com Foucault (1985) apontam a exatidão da atenção e vigilância para consigo mesmo, a apreensão com as perturbações do corpo e da alma e o respeito necessário para consigo mesmo.

O filósofo Epicteto define o cuidado de si como "[...] um privilégio-dever, um dom-obrigação que nos assegura a liberdade obrigando-nos a tornar-nos nós próprios como objeto de toda nossa aplicação" (FOUCAULT, 1985, p. 53). Este pensador parecia acreditar que o ser humano, diferentemente dos animais, seria o ser a quem foi confiado o cuidado de si e precisaria, então, aprender a realizá-lo com toda a atenção e empenho.

Foucault (2006) situa nos séculos I e II da nossa era a idade de ouro da cultura de si. Uma das principais formas do cuidado de si nesses primeiros séculos, nas épocas helenística e romana, parecia ser a dietética, regime do corpo e da alma. Foucault (1984, p. 93) refere que "[...] o regime é toda uma arte de viver". Neste sentido, o regime parecia ter um caráter normativo, problematizando o comportamento do indivíduo e compreendendo as medidas exatas dos exercícios, dos alimentos, das bebidas, dos sonos e particularmente das relações sexuais.

Foucault (1985, p. 107) comenta que a literatura de regime possuía o objetivo de assegurar a autonomia, reconhecendo nela "[...] um dos princípios essenciais da prática de si: armar-se, para tê-lo sempre a mão, de um discurso prestimoso cedo aprendido, freqüentemente repetido, e regularmente meditado". O regime não

Movimento, Porto Alegre, v. 14, n. 01, p. 187-198, janeiro/abril de 2008. 
estabelecia somente uma medida de ordem corporal, mas também de ordem moral, evidenciando um grande comprometimento com as obrigações da alma. A alma deveria manter completo domínio sobre si própria e o corpo não poderia prevalecer-se sobre ela. A alma parecia ser, portanto, o foco principal das atenções. Naquele momento histórico, a obrigação com o cuidado de si mesmo tomou aspecto de lei, abrangendo a todos incondicionalmente, durante toda a vida, indiferentemente do status social de cada um.

Deste modo, ao abranger toda a vida, a velhice também estaria incluída nesta prática de si e devia ser encarada como uma "meta positiva da existência" (FOUCAULT, 2006, p. 135). Mas a lei do cuidado consigo mesmo parece ser fictícia no que tange ao status social, apresentava-se como privilégio de elite, pois era preciso despender tempo e recursos erários para a manutenção deste cuidado. Então, como auxiliar nessas práticas de si, a aristocracia de Roma utilizava freqüentemente o consultor privado, um conselheiro que agregava diferentes funções e as desempenhava alternadamente como professor, guia, confidente pessoal, inspirador político e intermediário em negociações (FOUCAULT, 1985). Mas a assistência no cuidado de si não era feita somente por profissionais, circundava todas as relações sociais. A procura pela ajuda de uma outra pessoa com sabedoria e competência para auxiliar na aplicação de si era vista como um direito, assim como era dever desta outra pessoa ajudar a primeira. "O cuidado de si aparece, portanto, intrinsecamente ligado a um serviço de alma que comporta a possibilidade de um jogo de trocas com o outro e de um sistema de obrigações recíprocas" (FOUCAULT, 1985, p. 59).

Foucault (1985) também relata a correlação do cuidado de si e a prática médica na cultura grega, onde a atenção com o corpo foi intensificada com o incremento do cuidado médico. A filosofia e a medicina encontravam-se intimamente ligadas, regulamentando a vida dos indivíduos.

A partir dos séculos III e IV surge o cristianismo defendendo a renúncia de si como princípio fundamental para a salvação de si (FOUCAULT, 2006). A ocupação consigo mesmo aparece na forma

Movimento, Porto Alegre, v. 14, n. 01, p. 187-198, janeiro/abril de 2008. 
do conhecimento purificador, dissipando as tentações, ilusões e seduções e buscando a salvação da alma. O modelo cristão foi transmitido a toda história da cultura ocidental, portanto a alma continuou a representar o foco principal de todos os cuidados.

Atualmente, porém, vivemos em uma “[...] ordem tecnocientífica-empresarial [...]" (SANT'ANNA, 2005, p. 99) onde o corpo é o novo templo da subjetividade e a alma parece ter perdido sua relevância. Baudrillard (2005, p. 136) refere "[...] tudo hoje testemunha que o corpo se tornou objeto de salvação. Substitui literalmente a alma, nesta função moral e ideológica". A salvação do corpo parece ter suplantado a salvação da alma. Sant'Anna (2005, p. 103) também chama a atenção para esta mudança, defendendo que "[...] quando o corpo adquire o valor e o estatuto semelhantes ao da alma, é preciso conquistá-lo, e controlá-lo rapidamente, pois, diferente daquela, sabe-se que o corpo não possui vida eterna".

Sobre esta finitude do corpo, Bauman (2005) comenta que o corpo parece ser o único com expectativa de duração crescente, quando comparado ao estilo de vida, às instituições e aos objetos que servem à existência humana. Porém, mesmo evidenciando a possibilidade de "longo prazo" (BAUMAN, 2001), o corpo continua a ser mortal, não há uma data pré-estabelecida, mas a sua finitude é um fato concreto. Neste sentido Sant'Anna (2005, p. 103) nos remete à noção de prazo de validade:

[...] cuidar do corpo é aumentar o prazo de validade de suas várias partes, dilatá-los em direções diversas, para a seguir, reconfigurá-los; mesmo que, para isso, seja preciso modificar radicalmente a natureza de cada elemento vivo, criando novas vias para a evolução.

Assim, o prazo de validade parece não estar ligado unicamente ao tempo de duração etária deste corpo, mas à longevidade de sua aparência jovem. Nessa perspectiva, Baudrillard (2005, p. 151) acrescenta que "[...] o corpo transforma-se em objeto ameaçador que é preciso vigiar, reduzir e mortificar para fins estéticos". Uma enxurrada de informações nos assola diariamente através dos meios de comunicação que nos apresentam as últimas estatísticas sobre

Movimento, Porto Alegre, v. 14, n. 01, p. 187-198, janeiro/abril de 2008. 
os riscos dos quais temos a obrigação de proteger nosso corpo a fim de aumentar sua longevidade.

A bioestatística contemporânea, por exemplo, nos oferece números que, "[...] além de categorizar uma forma de conduzir o próprio corpo como um fator de risco, tratam cada sujeito que se encontra capturado nessa rede de incidências como protagonista dessa crônica da morte degenerativa" (FRAGA, 2006, p. 20). Deleuze $(1999$, p. 6) defende que "[...] informar é fazer circular uma palavra de ordem [...]" e explica que aqueles que nos informam dizem no que exatamente devemos crer. E parecem informar, também, o que precisamos temer.

A crença na necessidade da longevidade estética parece tê-la tornado um objetivo almejado de maneira incansável, incrementado pelo temor na chegada da velhice. Para Melucci (2004, p. 129) "[...] o envelhecer e o ser velho são temas que projetam uma sombra de inquietude sobre a sociedade solar, que celebra o culto do corpo jovem e eficiente". A velhice parece ter passado de uma meta positiva da vida (séculos I e II) para incorporar a negatividade da inutilidade. Assim, a fim de fugir do envelhecimento, do descarte, do lixo social, o corpo parece constituir-se em objeto de reinvenção constante e incansável. "Um corpo em reconstrução é infinito" (SANT'ANNA,2001, p. 65).

Desta forma, essa reconstrução parece significar correção, reforma, reorganização e adequação às aspirações de pertencimento às normas deste momento histórico. A intervenção de especialistas parece fazer-se necessária nesta reconstrução do corpo, oferecendo uma rede infindável de serviços e de aconselhamentos. Neste sentido, Melucci (2004, p. 105) defende que a vida cotidiana: "[....] não é mais o campo da experiência e das relações, mas um espaço de atenção e de intervenção para uma quantidade de especialistas que identificam problemas e nos propõe soluções". Para cada problema que surge parece ser necessária a orientação de um especialista, que prescreve, recomenda, receita e delimita as formas de agir do indivíduo, tornando-o dependente dos seus serviços.

Movimento, Porto Alegre, v. 14, n. 01, p. 187-198, janeiro/abril de 2008. 
Em relação a esta dependência, Bauman (2001, p.85) comenta que "[...] procurar exemplos, conselho e orientação é um vício: quanto mais se procura, mais se precisa e mais se sofre quando privado de novas doses da droga procurada". O personal trainer ou treinador personalizado parece ser um destes especialistas, um especialista em boa forma, um "mentor da corpolatria" (MALYSSE, 2002, p. 99). Segundo Oliveira (1999) o personal trainer seria o profissional licenciado em Educação Física com qualificação em treinamento desportivo, fisiologia do exercício, anatomia e biomecânica, apto para a prescrição de treinamento físico individualizado.

Entretanto, a atuação profissional do treinador personalizado não parece abranger somente o treinamento físico do cliente e seu exato momento de execução, mas a totalidade de seu cotidiano. Parece incluir, também, o controle da sua rotina diária, dos seus hábitos alimentares, dos seus horários de sono, do seu vestuário, das suas relações familiares e sociais; interferindo, muitas vezes, em suas decisões pessoais. Em um rápido olhar, o personal trainer parece ser a versão atualizada do consultor privado dos primeiros séculos.

No entanto, parecem existir diferenças cruciais entre estas duas figuras: o consultor privado objetivava o aconselhamento para assegurar a autonomia do indivíduo, enquanto o personal trainer parece visar à dependência eterna do cliente ao seu trabalho. $\mathrm{O}$ conselheiro auxiliava o indivíduo a cuidar-se a si mesmo, diferentemente dele, o personal trainer parece deter a responsabilidade pelo cuidado do seu cliente. Assim, o cliente parece transferir a preocupação por cuidar-se para o seu treinador personalizado, isentando-se desta função. Ao contrário dos conselheiros dos primeiros séculos que focavam a alma, o personal trainer parece focalizar os seus cuidados exclusivamente no corpo do seu cliente. Poderíamos dizer, então, que o corpo constitui-se o alvo do cuidado de si na atualidade e que o personal trainer parece ser um agente deste cuidado. Mas por que o cliente transferiria o cuidado de si para este especialista?

Movimento, Porto Alegre, v. 14, n. 01, p. 187-198, janeiro/abril de 2008. 
A individualização - característica crescente deste momento histórico - poderia ser pensada como uma possibilidade de discussão. Bauman (2001) defende que a individualização traz para o indivíduo, concomitantemente, a liberdade da experimentação e o enfrentamento das conseqüências. Enfrentar as conseqüências pelas escolhas ou simplesmente acertar nestas escolhas, parece gerar grande ansiedade na vida do consumidor. "Não dar conta de si mesmo, em sociedades nas quais o "si mesmo" tornou um negócio de total responsabilidade de cada um, torna-se um novo fantasma, tão terrível quanto o antigo fantasma das culpabilidades escondidas a sete chaves" (SANT'ANNA, 2001, p. 25).

A responsabilidade pelas escolhas parece ser exclusiva de cada indivíduo consigo mesmo e, para fugir do erro, da reprovação, da culpa, parece ser seguro delegar a responsabilidade de si para outra pessoa. Neste sentido, no que se refere ao corpo e seu cuidado, o personal trainer passaria a ser o alvo desta transferência de responsabilidade.

O serviço exercido pelo prestador personal trainer que objetiva o cuidado do corpo do cliente, poderia ser entendido como um objeto de compra, que adiciona símbolo de poder e status social ao seu comprador. Corpo e consumo parecem estar intimamente ligados: "[...] se a redescoberta do corpo é sempre a do corpo/objeto no contexto generalizado dos outros objetos, percebe-se como é fácil, lógica e necessária a transição da apropriação de bens e de objetos de compra" (BAUDRILLARD, 2005, p. 143).

Assim, podemos pensar que o status do cuidado de si parece ter se mantido inalterado desde a antiguidade, continuando a ser um privilégio de elite. $\mathrm{O}$ cuidado de si realizado pelo personal trainer poderia ser entendido como uma prestação de serviço exclusiva de uma elite econômica, que busca a constante metamorfose de um corpo que consome e é consumido. Neste sentido, Andrade e Janata (2003, p. 1) referem-se ao corpo como "[...] sinônimo de mercadoria plástica, a ser lapidada, preenchida, exposta e vendida [...]", o que corrobora com o pensamento de alguns dos autores aqui apresentados.

Movimento, Porto Alegre, v. 14, n. 01, p. 187-198, janeiro/abril de 2008. 


\section{Considerações TransitóRIAS}

A proposta deste artigo de revisão não é, de maneira alguma, encerrar a discussão que, por hora, parece demandar certa complexidade.

A temática do "cuidado de si" foi abordada neste artigo com o intuito de colocar o trabalho realizado pelo profissional de Educação Física, que atua como treinador personalizado, no centro da discussão. Neste sentido, este cuidado foi enfocado como um possível viés de mediação entre personal trainer e seu respectivo cliente, pois não parece se tratar de uma relação unilateral, mas de uma inter-relação.

O cuidado de si parece estar ligado ao trabalho do personal trainer indiretamente, perpassando, atravessando a relação cliente - treinador pessoal. Portanto, parece deslocar o papel deste profissional, que é focado no treinamento e na preparação física do seu cliente, para pensá-lo como um "cuidador" deste cliente. Assim, podemos pensar "o sentir-se cuidado" como uma possibilidade de sensação almejada pelo cliente na relação com seu personal trainer. O tensionamento desta relação é atravessado por questões que, aqui neste artigo, podem convergir com o conceito de cuidado de si. Este tensionamento parece carecer de discussões mais amplas da área de Educação Física e Ciências do Esporte, pois a bibliografia sobre o tema não tem se ocupado de investigá-lo.

Assim, a perspectiva de olhar para o tensionamento da relação do personal trainer com seu cliente poderia cotejar uma prática e uma teoria que permitissem problematizar esta complexidade, como a possibilidade da leitura a partir do cuidado de si.

Movimento, Porto Alegre, v. 14, n. 01, p. 187-198, janeiro/abril de 2008. 
The personal trainer and the care itself: a perspective of professional mediation.

Abstract: The present article proposed to discuss the "care itself" as a possibility of the professional mediation between the teacher of the Physical Education who work as personal trainer and his client. That why, was realized a bibliographic revision about the subject "care itself", used as theoretical support the works of the Michel Foucault, next the attempt of the articulation with the thought of the authors as Deleuze, Baudrillard, Bauman, Melucci and Sant'Anna, among others.

Keywords: Care Itself. Personal Trainer. Body.

El personal trainer y el cuidado de si: una pers-
pectiva de mediación profesional.
Resumen: El actual artículo propone discutir el "cui-
dado de si" como una posibilidad de mediación
profesional en medio el profesor de Educación Físi-
ca que trabaja como entrenador personalizado -
personal trainer - y su cliente. Para eso, fue realiza-
da una revisión bibliográfica sobre el tema "cuidado
de si", utilizando como soporte teórico el trabajo de
Michel Foucault, sucedida da tentativa de articulación
con el pensamiento de autores como Deleuze,
Baudrillard, Bauman, Melucci y Sant'Anna, en medio
otros.
Palabras-Clave: Cuidado de Si. Personal Trainer.
Cuerpo.

\section{REFERÊNCIAS}

ANDRADE, Roger Vidal França de; JANATA, Natacha Eugênia. Plasticidade, plástico e plásticas: por onde anda o corpo? In: CONGRESSO BRASILEIRO DE CIENCIAS DO ESPORTE, 2003, Caxambu. Anais... Caxambu: Colégio Brasileiro de Ciências do Esporte, 2003. 1 CD-ROM.

BAUDRILLARD, Jean. A Sociedade de Consumo. Lisboa: Edições 70, 2005.

BAUMAN, Zigmunt . Identidade. Rio de Janeiro: Jorge Zahar, 2005.

BAUMAN, Zigmunt. Globalização: as conseqüências humanas. Rio de Janeiro: Jorge Zahar, 1999.

BAUMAN, Zigmunt. Modernidade Líquida. Rio de Janeiro: Jorge Zahar, 2001.

Movimento, Porto Alegre, v. 14, n. 01, p. 187-198, janeiro/abril de 2008. 
BROOKS, Douglas S. Manual do Personal Trainer. Porto Alegre: Artmed,2000.

BROOKS, Douglas S. Treinamento Personalizado. São Paulo: Phorte, 2004.

DELEUZE, Gilles. O ato da criação. Folha de São Paulo, São Paulo, 27 jun. 1999, Caderno Mais, $4 \mathrm{p}$.

DELIBERADOR, Ângelo Peruca. Metodologia do desenvolvimento: personal training. Londrina: Midiograf,1998.

DOMINGUES FILHO, Luiz Antônio. Manual do Personal Trainer Brasileiro. São Paulo: Ícone, 2001.

FOUCAULT, Michel. A hermenêutica do sujeito. São Paulo: Martins Fontes, 2006.

FOUCAULT, Michel. História da sexualidade 2: o uso dos prazeres. Rio de Janeiro: Edições Graal, 1984.

FOUCAULT, Michel. História da sexualidade 3: o cuidado de si. Rio de Janeiro: Edições Graal, 1985.

FRAGA, Alex Branco. Exercício da informação: governo dos corpos no mercado da vida ativa. Campinas, SP: Autores Associados, 2006.

MALYSSE, Stéphane. Em busca dos $(\mathrm{H})$ alteres-ego: olhares franceses nos bastidores da corpolatria carioca. In: GOLDENBERG, Mirian (org.). Nu \& Vestido. Rio de Janeiro: Record, 2002. p. 79-137.

MELUCCI, Alberto. O jogo do eu: a mudança de si em uma sociedade global. São Leopoldo: Editora Unisinos, 2004.

MONTEIRO, Artur Guerrini. Treinamento Personalizado: uma abordagem didático-metodológica. São Paulo: Phorte, 2000.

MONTEIRO, Walace. Personal training: manual para avaliação e prescrição de condicionamento físico. Rio de Janeiro: Sprint,1998.

NOVAES, Jefferson S. Personal training e condicionamento em academia. Rio de Janeiro: Shape, 1998.

NOVAES, Jefferson S.; VIANNA, Jeferson M. Personal training e condicionamento físico em academia. Rio de Janeiro: Shape, 2003.

O'BRIEN, Teri S. O Manual do Personal Trainer. São Paulo: Manole, 1998.

OLIVEIRA, Roberto Cesar de. Personal Training. São Paulo: Atheneu, 1999.

RODRIGUES, Carlos Eduardo Cossenza. Personal Training. Rio de Janeiro: Sprint, 1996.

Movimento, Porto Alegre, v. 14, n. 01, p. 187-198, janeiro/abril de 2008. 
RODRIGUES, Carlos Eduardo Cossenza; CONTURSI, Ernani Bevilaqua. Manual do Personal Trainer. Rio de Janeiro: Sprint, 1998.

SANT'ANNA, Denise. Corpos de passagem: ensaios sobre a subjetividade contemporânea. São Paulo: Estação Liberdade, 2001.

SANT'ANNA, Denise. Transformações do corpo: controle de si e uso dos prazeres. In: RAGO, Margareth; ORLANDI, Luiz B. Lacerda; VEIGA-NETO, Alfredo (Org.). Imagens de Foucault e Deleuse: ressonâncias nietzschianas. Rio de Janeiro: DP\&A, 2005.

SIBILLIA, Paula. O homem pós-orgânico: corpo, subjetividade e tecnologias digitais. Rio de Janeiro: Relume Dumará, 2002.

Movimento, Porto Alegre, v. 14, n. 01, p. 187-198, janeiro/abril de 2008. 